\title{
Simulation and Comparison of the Lighting Efficiency for Household Illumination with LEDs and Fluorescent Lamps
}

\author{
Wen-Shing Sun ${ }^{1}$, Chuen-Lin Tien ${ }^{2 *}$, Jui-Wen Pan ${ }^{3}$, Tsung-Hsun Yang ${ }^{1}$, Chih-Hsuan Tsuei ${ }^{1}$, \\ and Yi-Han Huang ${ }^{1}$ \\ ${ }^{1}$ Department of Optics and Photonics, National Central University, 32001 Chungli, Taiwan, ROC. \\ ${ }^{2}$ Department of Electrical Engineering, Feng Chia University, 40724 Taichung, Taiwan, ROC. \\ ${ }^{3}$ Institue of Photonic System, National Chiao Tung University, 71150 Tanan, Taiwan, ROC.
}

(Received July 1, 2013 : revised August 1, 2013 : accepted September 23, 2013)

\begin{abstract}
The design of the LEDs lighting in general household illumination was proposed and compared with the fluorescent lighting in this study. Using the LED as a light source would promote energy saving lighting for household illumination purposes. We used the LightTools and DIALux software to design and simulate different standards of illuminance, different correlated color temperatures and different color rendering indices for household environments. The power consumption and efficiency of traditional illuminated light sources and an LED light source with the same standard of illuminance for lighting the household environment were analyzed and compared with each other. Finally, our results show the advantages of using white-light LEDs for lighting and household illumination.
\end{abstract}

Keywords : Light-emitting diodes, Indoor lighting, Color temperature, Color rendering

OCIS codes : (080.4295) Nonimaging optical systems; (220.2945) Illumination design; (230.3670) Light-emitting diodes; (330.0330) Vision, color, and visual optics

\section{INTRODUCTION}

Although fluorescent lights are often used in our daily life, they still have some problems, such as short lifetime, excessive power consumption, and mercury pollution [1]. To solve these problems, we must try to develop more environmentally-friendly light sources. One of the most promising types for future development is light emitting diodes (LEDs).

Rapid improvement of the efficiency of high power LEDs has been made during these past several decades leading to a wide variety of LED applications, giving us different visions in lighting design. The current advantages of LEDs mean that they can now surpass traditional light sources [2]. Furthermore, updated legislation which demands consideration of the environmental impact of a product over its life cycle, from production to disposal, makes LEDs the ideal candidate for an environmentally-friendly light source [3]. Already, numerous tiny glowing LED indicators are utilized in modern households for transmitting signals or information from electronic equipment [4]. Increasingly, automobiles are also being equipped with LED indicators and brake lights. Recently LED head lights have been designed for use in concept cars [5], and rapid improvements in white LEDs, such as for street lights, have been made in the worldwide multi-billion dollar lighting market. These changes and the worldwide development of LED based illumination systems should make it possible for LEDs to be used in interior household illumination in the near future [6-11].

\section{METHOD}

During the past several decades, fluorescent lights have become commonly used for daily illumination. The luminaires for fluorescent light vary. The most commonly used in our households are twist-style compact fluorescent lamps. In addition, the development of LED techniques means that traditional illumination sources such as fluorescent lamps are no longer suitable. This is the reason we make a

\footnotetext{
*Corresponding author: chuenlintien@yahoo.com

Color versions of one or more of the figures in this paper are available online.
} 
comparison between the twist-style compact fluorescent lamps and white-light LEDs.

\subsection{Light Sources}

Two kinds of different light sources that represent two different generations of development are described below. A Philips HELIX 23W CDL twist-style compact fluorescent lamp (with $23 \mathrm{~W}$ and $1450 \mathrm{~lm}$ performance) and a HELIX 23W WW twist-style compact fluorescent lamp (with 23W and $1550 \mathrm{~lm}$ performance) are both commonly used as single light sources for general household illumination. These two twist-style compact fluorescent lamps are the same in appearance, as shown in Fig. 1(a). In this study, we simulated three different LEDs for lighting the same household environment. The performance of these different LEDs is described as follows: one is the Lumileds LXML-PW51; another is the Lumileds LXM3-PW51; the other is the Lumileds LXM3-PW71. In appearances they are the same as shown in Fig. 1(b). The relative spectral power distributions of these three LEDs are shown in Fig. 2. All of the parameters for these light sources are listed in Table 1[12]. If the value of $\mathrm{R} 9$ is too low or is negative, then its value is not listed. The reasons for choosing Philips compact

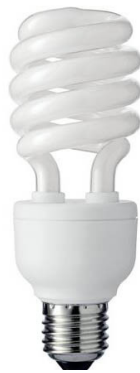

(a)

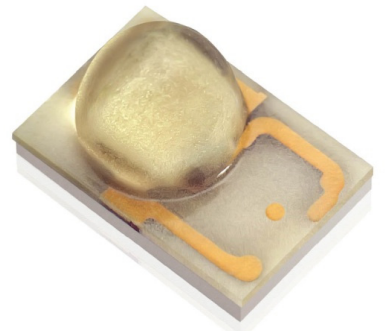

(b)
FIG. 1. Layout of (a) Philips HELIX 23W CDL/WW twist-style compact fluorescent lamp; (b) Philips Lumileds LED.

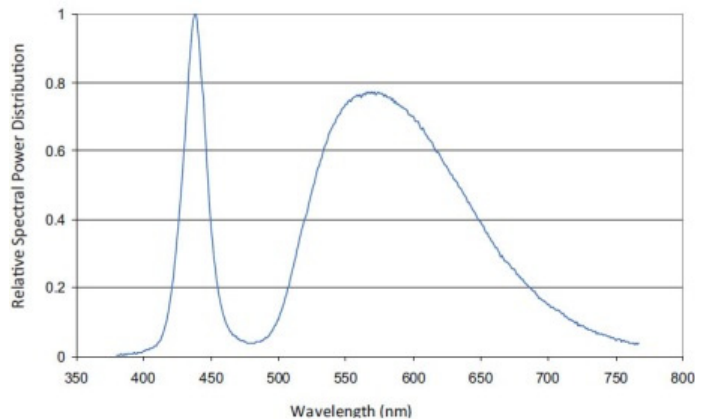

(a)

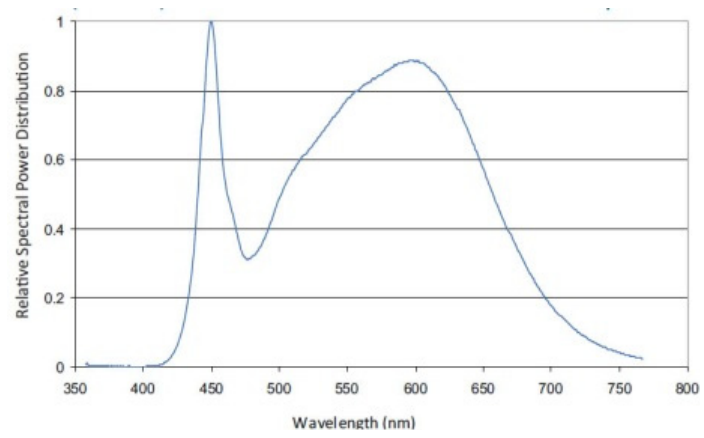

(b)

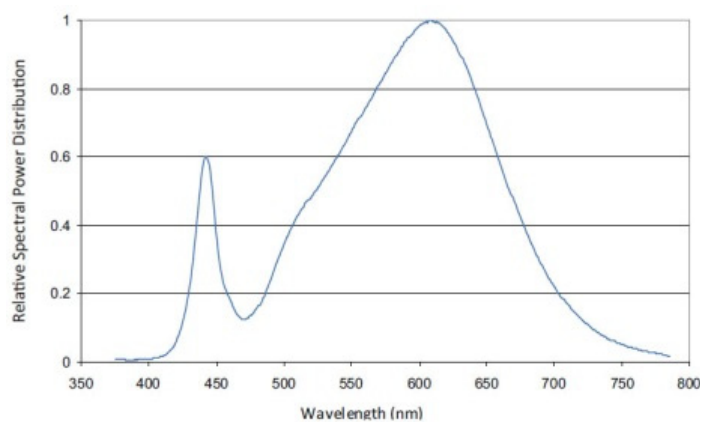

(c)

FIG. 2. Relative spectral power distributions of: (a) LXMLPW51, (b) LXM3-PW51 and (c) LXM3-PW71.

TABLE 1. Parameters of the three different LEDs and two fluorescent lamps

\begin{tabular}{|c|c|c|c|c|}
\hline & LED 1 & LED 2 & LED 3 & $\begin{array}{l}\text { Twist-shape compact } \\
\text { fluorescent lamp }\end{array}$ \\
\hline Type & $\begin{array}{c}\text { Lumileds } \\
\text { LXML-PW51 }\end{array}$ & $\begin{array}{c}\text { Lumileds } \\
\text { LXM3-PW51 }\end{array}$ & $\begin{array}{c}\text { Lumileds } \\
\text { LXM3-PW71 }\end{array}$ & $\begin{array}{l}\text { Philips HELIX } \\
\text { 23W CDL/WW }\end{array}$ \\
\hline Nominal CCT $(\mathrm{K})$ & 4000 & 4000 & 3000 & $6500 / 2700$ \\
\hline Typical CRI (Ra) & 70 & 85 & 85 & 82 \\
\hline Typical R9 & -- & 28 & 22 & --- \\
\hline Typical Luminous Flux (lm) & 105 & 85 & 77 & $1450 / 1550$ \\
\hline Power (W) & 1.05 & 1.05 & 1.05 & 23 \\
\hline Efficiency $(\mathrm{lm} / \mathrm{W})$ & 100 & 81 & 73 & $63 / 67$ \\
\hline Proper Area & $\begin{array}{l}\text { Porch area, Living room } \\
\text { area, parents' room area, } \\
\text { reading room area, stairs. }\end{array}$ & $\begin{array}{l}\text { Kitchen areaand dining } \\
\text { room area. }\end{array}$ & $\begin{array}{c}\text { Master bedroom area } \\
\text { and children's room } \\
\text { area. }\end{array}$ & All areas. \\
\hline
\end{tabular}


fluorescent lamps and Lumileds LEDs for the household lighting simulation are their low market price, low power consumption, high luminous flux, suitable correlated color temperature (CCT) and high color rendering index (CRI).

As a consequence of the time that they became available in the lighting market, these twist-style compact fluorescent lamp and LEDs were used in the simulation and comparison for household illumination. We were able to obtain the candle power distribution profiles from the Philips Lumileds website and used the profiles to simulate the household illumination with different types of reflectors with the LightTools optical design software.

\subsection{Reflector}

The reflector is simply a device, like a mirrored reflected plane, used to alter the path of the light trace. Reflectors play an important role in a lighting system. In this work, all the home lighting fixtures are designed by using parabolic reflectors, as shown in Fig. 3. Given the parabolic reflector design, the distance $d$ between the light source point (focal point) and the reflective surface can be calculated for each single light source [13]. The parabolic reflector design is described for the spatial model of our simulated household.

\subsection{Space Model}

Regarding the spatial model in the case study, a two floor house was chosen to simulate the household illumination. The layout may vary with a porch area, a living room, a reading room, a dining room, and a kitchen located on the first floor. All bedrooms including the master bedroom, children's room, and parent's room are placed on the second floor. Other spaces such as the bathroom and stairs are also considered. The dimensions of the vertical views of all different areas are shown in Fig. 4. Therefore, different correlated color temperatures (CCT) and color rendering indices (CRIs) are also investigated and suited to different household illumination environments.

\subsection{Correlated Color Temperature (CCT) and Color Rendering Index (CRI)}

The market price, power consumption and luminous flux of the light source are all easily available to the general consumers, but the CCT and CRI are not. Consumers are often concerned about the price and power consumption, but most do not consider the correlated color temperature or what a color rendering index is. The CCT is a characteristic of visible light that is becoming more and more important in indoor lighting in recent years. The CCT of a light source is the temperature of an ideal black-body radiator that radiates light of comparable hue to that of the light source. Color temperature is conventionally stated in units of absolute temperature, the Kelvin, having the unit symbol $\mathrm{K}$. The related present color is shown in the CIE chromaticity diagram [14]. Consider for example, consumers might want their living room design to have a feeling of warmth,

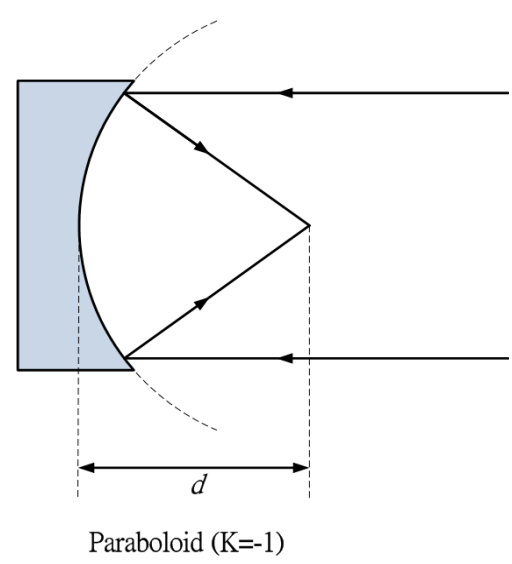

FIG. 3. Distance between the light source point (focal point) and the reflective surface of the parabolic surface.

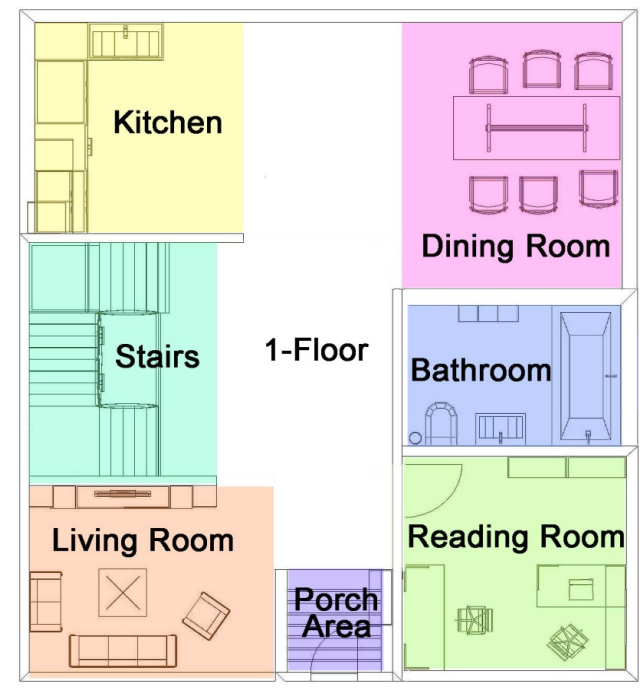

(a)

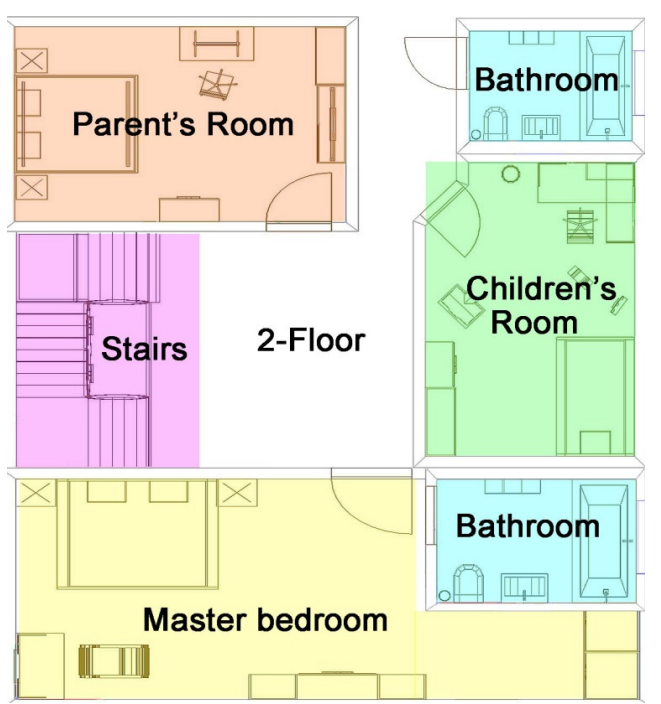

(b)

FIG. 4. Vertical views of (a) the first floor and (b) the second floor in the spatial model. 
meaning a lower CCT light source could be used to light this kind of warm space. Illumination with low CCT brings a warm feeling to the environment; on the other hand, illumination with high CCT brings a cool feeling $[15,16]$.

The CIE color rendering index (CRI) is a method to determine how well a light source's illumination compares to the illumination provided by a reference source, such as black body radiation, defined as having a CRI of 100 . Incandescent lamps have a rating almost the same as black body radiators. The best possible faithfulness to a reference is specified by a CRI of one hundred, while the very poorest is specified by a CRI of zero. The color of the illuminated object will completely reappear when the CRI of a light source reaches 100; otherwise, the reappeared color will be decreased [17, 18]. In kitchens, for example, the CRI is an important index for the evaluation of the appearance of food, for social interaction, and for complementing decorative finishes. That means that the higher the CRI of LEDs that can be used for lighting this kind of colorful space, the better its rendering ability for making fish, vegetables and fruits look fresh and delicious. Thus, the CRI and the CCT give a numerical estimate of which ideal light source best approximates a particular artificial light, and what the difference is.

\section{SIMULATION RESULTS}

After building the light source models, we build the spatial model of the study area. It includes a porch area, a living room, a dining room, a children's room, a parents' room, a reading room, a master bedroom, a kitchen, a bathroom and the stairs area. Considering the different purposes of the different areas, we designed different light sources for household lighting, following the required Chinese National Standards (CNS) [19]. Then, we simulated the household lighting with general twist-style compact fluorescent lamps and LEDs, on a case by case basis. The simulated average illuminances and the required standard average illuminances for different areas are listed in Table 2. The simulation results all met the required standards.

\subsection{LED Lighting}

The Lumileds LXML-PW51, which has a high luminous flux, was chosen for lighting those spaces where people meet together, where older people might need a brighter environment or where more light is needed to read. This type of light was used in areas such as the porch area, living room, parents' room, reading room and stairs. The Lumileds LXM3-PW51, which has a higher CRI, was chosen when it was important to make things looks more colorful or make food look more appealing such as in the kitchen and dining room. The Lumileds LXM3-PW71, which has a warmer CCT, was chosen for comfortable areas such as the master bedroom, children's room and bathroom.

\subsection{Comparison}

In the simulation, the same required standard illuminance is utilized for every area. Given this we calculate and compare the electrical power consumption of twist-style compact fluorescent lamps and LEDs used in different household lighting environments. The energy consumption for lighting by a single twist-style compact fluorescent lamp is $23 \mathrm{~W}$ while the consumption for lighting of a single LED is $1.05 \mathrm{~W}$. The calculated power consumption of LED illumination is less than that of twist-style compact fluorescent lamps. Table 3 describes the use of home lighting white LEDs and fluorescent light sources, which used in various fields with fluorescent and white light LED quantity numbers, and shows the percentage of area power consumption over total power consumption.

TABLE 2. Illuminance of different areas inside the house model

\begin{tabular}{c|c|c|c}
\hline & $\begin{array}{c}\text { Required standard } \\
\text { Avg. illuminance }\end{array}$ & $\begin{array}{c}\text { Simulated } \\
\text { Avg. illuminance } \\
\text { (LED) }\end{array}$ & $\begin{array}{c}\text { Simulated } \\
\text { Avg.illuminance } \\
\text { (florescent lamp) }\end{array}$ \\
\hline Porch area & $75 \sim 150$ lux & 97.21 lux & 100.15 lux \\
\hline Living room area & $150 \sim 300$ lux & 280.70 lux & 278.83 lux \\
\hline Dining room area & $200 \sim 500$ lux & 328.09 lux & 330.34 lux \\
\hline Kitchen area & $200 \sim 500$ lux & 348.83 lux & 342.68 lux \\
\hline Reading room area & $50 \sim 100$ lux & 93.54 lux & 90.24 lux \\
\hline Master room area & $30 \sim 75$ lux & 73.53 lux & 70.93 lux \\
\hline Children's room area & $100 \sim 300$ lux & 144.97 lux & 150.57 lux \\
\hline Parents' room area & $100 \sim 200$ lux & 149.55 lux & 151.41 lux \\
\hline Bathroom area & $75 \sim 150$ lux & 119.29 lux & 115.51 lux \\
\hline Stairs area & $30 \sim 75$ lux & 59.62 lux & 55.41 lux \\
\hline
\end{tabular}




\subsection{Simulation Results by using DIALux and LightTools}

By using these LED designs for every room area, we use DIALux and LightTools simulation tools. DIALux and LightTools have the advantages of combining the human factors and quantitative simulation. We used a complementary method to design household illuminations, and the proposed approach was effective and feasible for the home lighting design. Fig. 5 shows the 3-D lighting in different areas by using the DIALux software. DIALux software can offer the feeling of color temperature in the environment and realistic visualizations. In the human factors aspects, DIALux is a better simulation software. Figure 5(a) shows the

TABLE 3. Power consumption for different light sources for the same illuminance standard

\begin{tabular}{|c|c|c|c|c|c|c|}
\hline \multirow[b]{2}{*}{ Type } & \multicolumn{3}{|c|}{ White light LEDs } & \multicolumn{3}{|c|}{ Florescent lamps } \\
\hline & Quantity & Power & Percent & Quantity & Power & Percent \\
\hline Porch area & 24 & $25.2 \mathrm{~W}$ & $5.00 \%$ & 2 & $46 \mathrm{~W}$ & $5.00 \%$ \\
\hline Living room & 96 & $100.8 \mathrm{~W}$ & $20.00 \%$ & 6 & $138 \mathrm{~W}$ & $15.00 \%$ \\
\hline Dining room & 12 & $12.6 \mathrm{~W}$ & $2.50 \%$ & 3 & $69 \mathrm{~W}$ & $7.50 \%$ \\
\hline Kitchen & 60 & $63 \mathrm{~W}$ & $12.50 \%$ & 5 & $115 \mathrm{~W}$ & $12.50 \%$ \\
\hline Reading room & 32 & $33.6 \mathrm{~W}$ & $6.67 \%$ & 4 & $92 \mathrm{~W}$ & $10.00 \%$ \\
\hline Master's room & 44 & $46.2 \mathrm{~W}$ & $9.17 \%$ & 4 & $92 \mathrm{~W}$ & $10.00 \%$ \\
\hline Children's room & 90 & $94.5 \mathrm{~W}$ & $18.75 \%$ & 4 & $92 \mathrm{~W}$ & $10.00 \%$ \\
\hline Parents' room & 80 & $84 \mathrm{~W}$ & $16.67 \%$ & 7 & $161 \mathrm{~W}$ & $17.50 \%$ \\
\hline Bathroom & 24 & $25.2 \mathrm{~W}$ & $5.00 \%$ & 2 & $46 \mathrm{~W}$ & $5.00 \%$ \\
\hline Stairs area & 18 & $18.9 \mathrm{~W}$ & $3.75 \%$ & 3 & $69 \mathrm{~W}$ & $7.50 \%$ \\
\hline Total & 480 & $504 \mathrm{~W}$ & $100 \%$ & 40 & $920 \mathrm{~W}$ & $100 \%$ \\
\hline
\end{tabular}

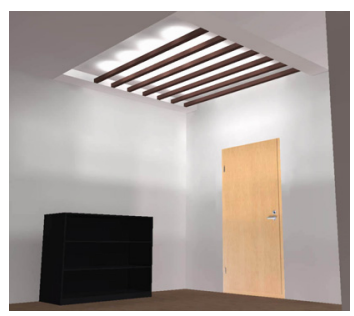

(a)

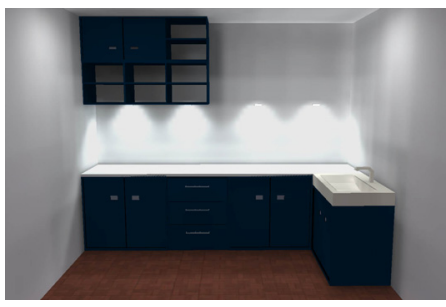

(d)

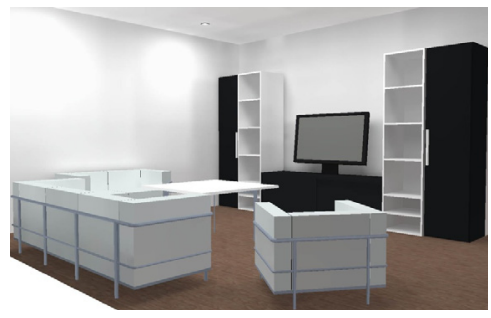

(b)

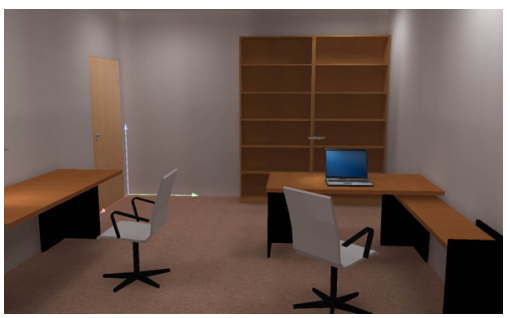

(e)

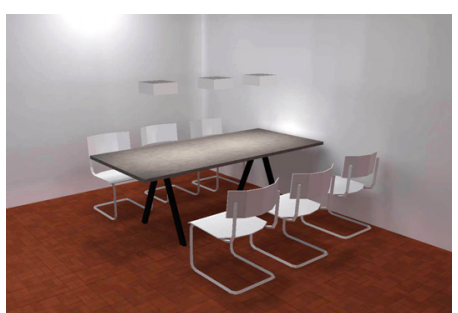

(c)

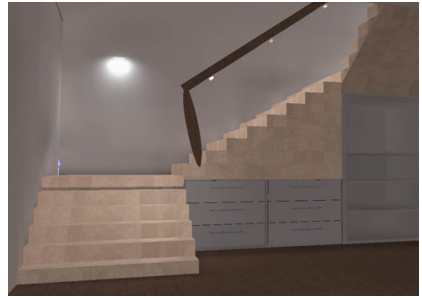

(f)

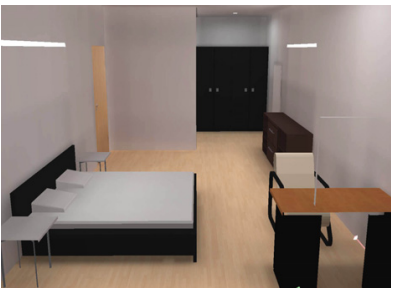

(g)

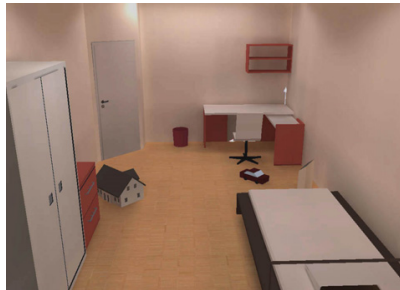

(h)

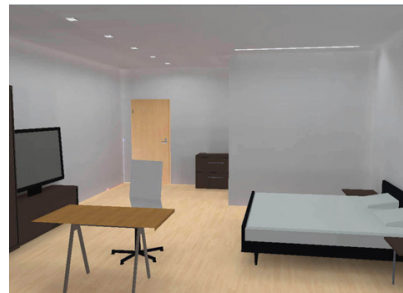

(i)

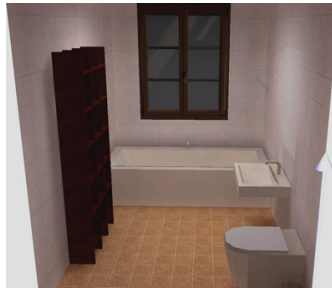

(j)

FIG. 5. 3-D lighting simulation in the: (a) porch, (b) living room, (c) dining room, (d) kitchen, (e) reading room, (f) stairs, (g) master bedroom, (h) children's room, (i) parents' room, and the (j) bathroom area. 


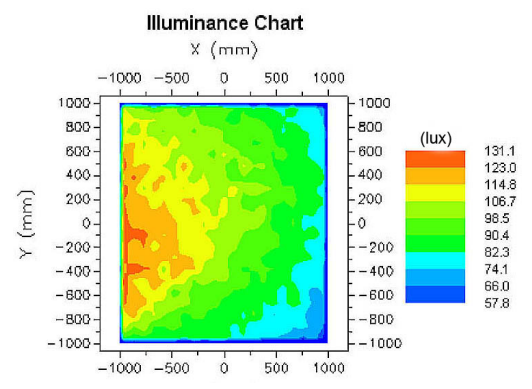

(a)

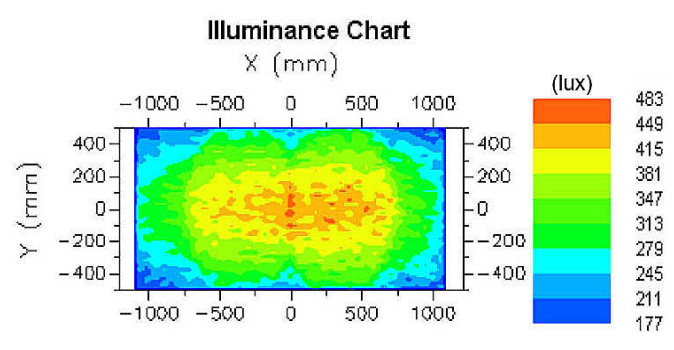

(c)

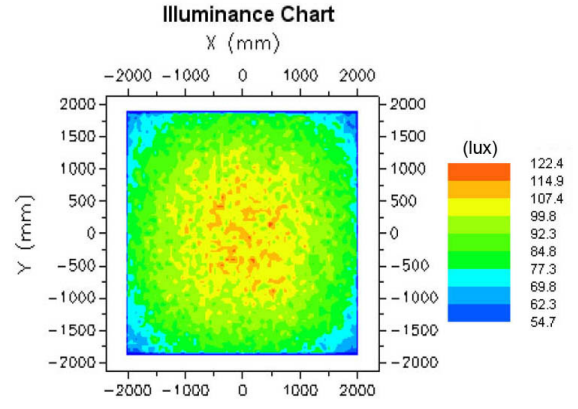

(e)

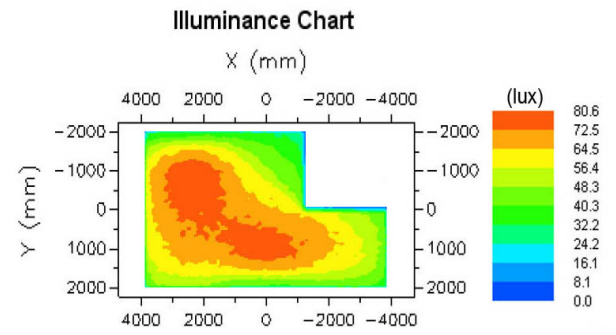

(g)

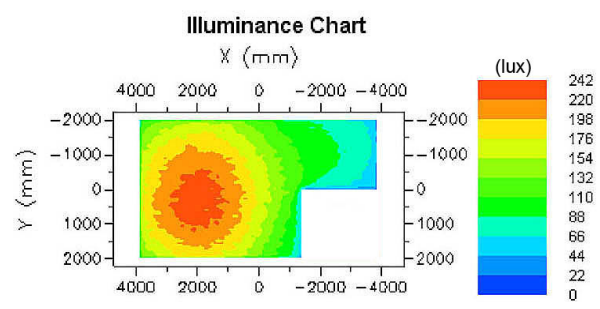

(b)

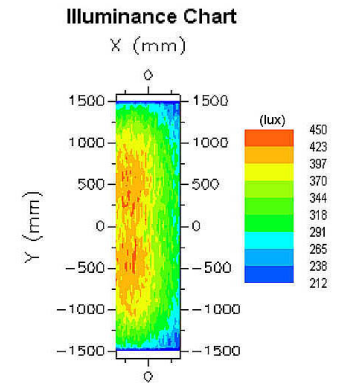

(d)

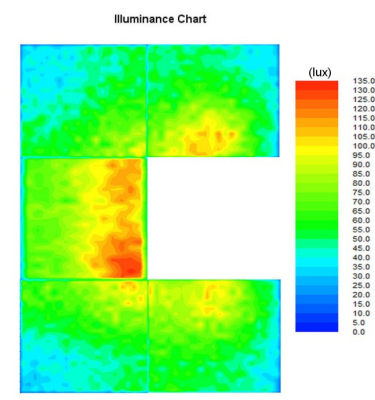

(f)

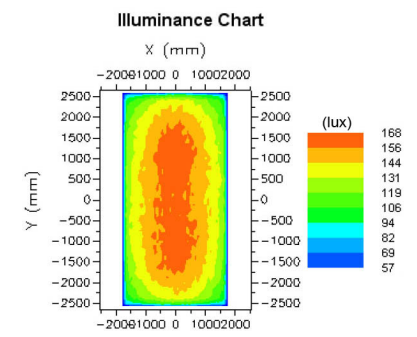

(h)

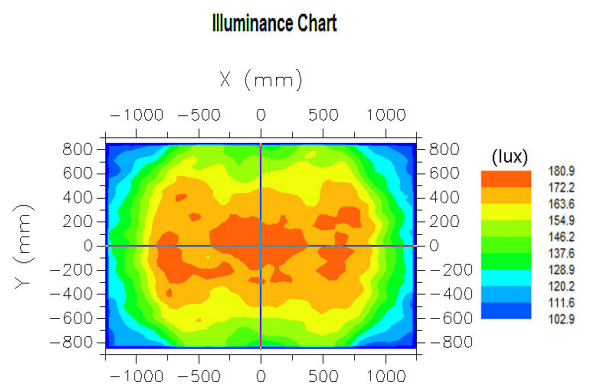

(i)

FIG. 6. The illuminance distributions of the: (a) porch, (b) living room, (c) dining room, (d) kitchen, (e) reading room, (f) stairs, (g) master bedroom, (h) children's room, (i) parents' room. 
porch lighting design which consists of 24 LED 1 to be a whitish $(\mathrm{CCT}=4000 \mathrm{~K}, \mathrm{CRI}=70)$ light source. Figure 5(b) illustrates the living room lighting design which consists of 96 LED 1 to be a whitish $(\mathrm{CCT}=4000 \mathrm{~K}, \mathrm{CRI}=70$ ) light source. Figure 5(c) shows the lighting design of the dining room which consists of 12 LED 2 to be a whitish $(\mathrm{CCT}=4000 \mathrm{~K}, \mathrm{CRI}=85)$ light source. In order to increase the appetite, we selected a high color rendering light source. Figure 5(d) illustrates the lighting design of the kitchen area which consists of 60 LED 2 to be a whitish $(\mathrm{CCT}=4000 \mathrm{~K}, \mathrm{CRI}=85)$ light source. Figure 5(e) shows the reading room lighting design which consists of 32 LED 1 to be a whitish $(\mathrm{CCT}=4000 \mathrm{~K}, \mathrm{CRI}=70)$ light source. Figure 5(f) shows the lighting design of the stair area which consists of 18 LED 1 to be a whitish (CCT = $4000 \mathrm{~K}, \mathrm{CRI}=70$ ) light source. Figure $5(\mathrm{~g})$ shows the lighting design of the master bedroom which consists of 44 LED 3 to be a yellowish $(\mathrm{CCT}=3000 \mathrm{~K}$, CRI $=85)$ light source. In order to increase the appetite, we select a high color rendering light source. To enhance the romantic atmosphere, we select a yellowish light with high color rendering index. Figure 5(h) shows the lighting design of the children's room which consists of 44 LED 3 to be a yellowish $(\mathrm{CCT}=3000 \mathrm{~K}, \mathrm{CRI}=85)$ light source. Figure 5(i) shows the lighting design of the parents' room which consists of 80 LED 1 to be a whitish (CCT $=4000 \mathrm{~K}$, CRI $=70$ ) light source. Figure 5(j) shows the lighting design of the bathroom which consists of 24 LED 2 to be a whitish $(\mathrm{CCT}=4000 \mathrm{~K}, \mathrm{CRI}=85)$ light source.

Figure 6 illustrates the illuminance distributions of every room area which is simulated by LightTools software. LightTools software calculates the values of illuminance in more detail, thus the simulation is more accurate in the quantitative aspects. Figure 6(a) shows the porch lighting design which consists of 24 pieces LED 1, the output power of $25.2 \mathrm{~W}$, output flux of $2400 \mathrm{~lm}$, illumination area of $2 \mathrm{~m} \times 2 \mathrm{~m}$. Most of the illuminance distribution is $74.1 \mathrm{~lx}$ to $131.1 \mathrm{~lx}$, and the porch lighting design meets the illuminance standards in the range of $75 \mathrm{~lx}$ to $150 \mathrm{~lx}$. Figure 6(a) shows the living room which consists of 96 pieces LED 1, the output power of $100.8 \mathrm{~W}$, output flux of $10080 \mathrm{~lm}$, illumination area of $8 \mathrm{~m} \times 4 \mathrm{~m}$. The illuminance distribution of living room lighting design is from $110 \mathrm{~lx}$ to $242 \mathrm{~lx}$. The living room lighting design is close to the illuminance standards in the range of $150 \mathrm{~lx}$ to $300 \mathrm{~lx}$. Figure 6(c) illustrates the dining room lighting design which consists of 12 pieces LED 2, the output power of $12.6 \mathrm{~W}$, output flux of $1020 \mathrm{~lm}$, illumination area of $2 \mathrm{~m} \times 1 \mathrm{~m}$. Most of the illuminance distribution is $211 \mathrm{~lx}$ to $483 \mathrm{~lx}$. The dining room lighting design meets the illuminance standards in the range of $200 \mathrm{~lx}$ to $500 \mathrm{~lx}$. Figure 6(d) shows the kitchen area lighting design which consists of 60 pieces LED 2, the output power of $63 \mathrm{~W}$, output flux of $5100 \mathrm{~lm}$, illumination area of $3 \mathrm{~m} \times 0.75$ $\mathrm{m}$. The illuminance distribution is $212 \mathrm{~lx}$ to $450 \mathrm{~lx}$. The kitchen lighting design meets the illuminance standards in the range of $200 \mathrm{~lx}$ to $500 \mathrm{~lx}$. Figure 6(e) indicates the reading room lighting design which consists of 32 pieces LED 1, the output power of $33.6 \mathrm{~W}$, output flux of 3360 $1 \mathrm{~m}$, illumination area of $4 \mathrm{~m} \times 4 \mathrm{~m}$. The reading room requires an auxiliary lamp on the desk and other places do not require excessive lighting. The illuminance distribution is $54.7 \mathrm{~lx}$ to $122.4 \mathrm{~lx}$. The reading room lighting design is close to the illuminance standards in the range of $50 \mathrm{~lx}$ to $100 \mathrm{~lx}$. Figure 6(f) illustrates the stair area lighting design which consists of 18 pieces LED 1, the output power of $18.9 \mathrm{~W}$, output flux of $1890 \mathrm{~lm}$. The illuminance distribution is $30 \mathrm{~lx}$ to135 $\mathrm{lx}$. The stair area design is over the lighting standards in the range of $30 \mathrm{~lx}$ to $75 \mathrm{~lx}$. Figure $6(\mathrm{~g})$ shows the master bed room lighting design which consists of 44 pieces LED 3, the output power of $46.2 \mathrm{~W}$, output flux of $3388 \mathrm{~lm}$, illumination area of $8 \mathrm{~m} \times 4 \mathrm{~m}$. The master bedroom lighting requirements are not very high and other places do not require excessive lighting. The illuminance distribution is $32.2 \mathrm{~lx}$ to $80.6 \mathrm{~lx}$. The master bedroom design is close the lighting standards in the range of $30 \mathrm{~lx}$ to $75 \mathrm{~lx}$. Figure 6(h) shows the children's room lighting design which consists of 90 pieces LED 3, the output power of $94.5 \mathrm{~W}$, output flux of $6930 \mathrm{~lm}$, illumination area of $5 \mathrm{~m} \times 3 \mathrm{~m}$. Most of the illuminance distribution is $94 \mathrm{~lx}$ to $168 \mathrm{~lx}$, and the children's room design meets the lighting standards in the range of $100 \mathrm{~lx}$ to $300 \mathrm{~lx}$. Figure 6(i) shows the parents' room lighting design which consists of 80 pieces LED 1, the output power of $84 \mathrm{~W}$, output flux of $8400 \mathrm{~lm}$, illumination area of $2.5 \mathrm{~m} \times 1.6 \mathrm{~m}$. The illuminance distribution is $102.9 \mathrm{~lx}$ to $180.9 \mathrm{~lx}$. The parents' room design meets the lighting standards in the range of $100 \mathrm{~lx}$ to $200 \mathrm{~lx}$.

\subsection{Twist-style Compact Fluorescent Lighting}

As regards the present lighting situation for the general populace, PHILPS HELIX $23 \mathrm{~W}$ CDL/WW is commonly used for lighting all areas. The required standard illuminance is also strictly followed in the simulation process. Based on the same CRI performance of these two fluorescent lamps, we only consider the required conditions of luminous flux and CCT at different lighting environments.

\section{CONCLUSION}

In this study, we simulated and analyzed twist-shape compact fluorescent lamps and LED light sources for use in household illumination. The simulations show the most advantageous LED lighting design and its benefits compared with a traditional twist-style compact fluorescent lamp in household lighting given the same required standard of illuminance. In addition, the LightTools and the DIALux simulation tools allowed us to easily simulate the illuminance and 3-D virtual reality. In the human factors aspects, DIALux software offers a more realistic simulation. LightTools can calculate the values of illumination in more detail, thus the 
simulation is more excellent in the quantitative aspects. Finally, we point out the possibility of using LED designs for accurate illumination applications.

\section{ACKNOWLEDGMENT}

This study was sponsored by the National Science Council under contract number NSC 101-2221-E-008-107.

\section{REFERENCES}

1. W. W. Jr. Tunnessen, K. J. McMahon, and M. Baser, "Acrodynia: exposure to mercury from fluorescent light bulbs," Pediatrics 79, 786-9 (1987).

2. R. Devonshire, "The competitive technology environment for LED lighting," J. Light \& Vis. Env. 3, 275-287 (2008).

3. N. Zheludev, "The life and times of the LED- a 100-year history," Nature Photonics 4, 189-192 (2007).

4. S. Liu, A. Minato, S. Ozawa, and M. Nakagawa, "A new lighting communication system for audio signal with white LED," J. Light \& Vis. Env. 2, 65-69 (2007).

5. A. J. W. Whang, P. C. Li, Y. Y. Chen, and S. L. Hsieh, "Guiding light from LED array via tapered light pipe for illumination systems design," J. Display Technol. 5, 104108 (2009).

6. T. Yorifuji, M. Sakai, T. Yasuda, A. Maehara, A. Okada, T. Gouriki, and T. Mannami, "Light source and ballast circuits," J. Light \& Vis. Env. 31, 157-172 (2007).

7. R. Allan, "LEDs lighten the energy load," Electronic Design 55, 55-58 (2007).
8. D. X. Wang, I. T. Ferguson, and J. A. Buck, "GaN-based distributed Bragg reflector for high-brightness LED and solid-state lighting," Appl. Opt. 46, $4763-4767$ (2007).

9. T. Taguchi, "Developing white LED Lighting systems and its technological roadmap in Japan," J. Light \& Vis. Env. 30, 177-182 (2006).

10. C. H. Tsuei, J. W. Pen, and W. S. Sun, "Simulating the illuminance and the efficiency of the LED and fluorescent lights used in indoor lighting design," Opt. Express 16, 18692-18701 (2008).

11. C. H. Tsuei, W. S. Sun, and C. C. Kuo, "Hybrid sunlight/ LED illumination and renewable solar energy saving concepts for indoor lighting," Opt. Express 18, A640-A653 (2010).

12. http://www.philipslumileds.com/products/luxeon-rebel/luxeon -rebel-white.

13. D. Malacara, Optical Shop Testing (John Wiley \& Sons, Inc., New York, USA, 1992).

14. Color Temperature, "http://wiki.fisski.com/index.php/Color Temperature".

15. H. Nakamura and Y. Karasawa, "Relationship between illuminance and color temperature and preference of atmosphere," J. Light \& Vis. Env. 23, 29-38 (1999).

16. H. Noguchi and T. Sakaguchi, "Effect of illuminance and color temperature on lowering of physiological activity," Appl. Human Sci. 18, 117-23 (1999).

17. K. C. Lin, "Approach for optimization of the color rendering index of light mixtures," J. Opt. Soc. Am. A 27, 15101520 (2010).

18. G. Cheng, M. Mazzeo, S. D’Agostino, F. D. Sala, S. Carallo, and G. Gigli, "Pure white hybrid light-emitting device with color rendering index higher than 90," Opt. Lett. 35, 616-618 (2010).

19. Chinese National Standards, "http://www.cnsonline.com.tw/". 